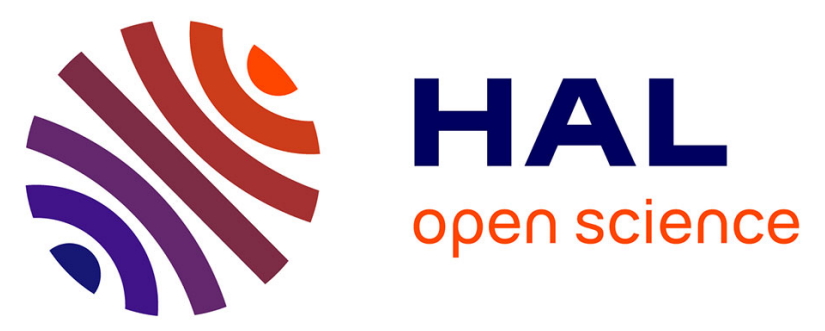

\title{
Long-period magnetospheric-ionospheric perturbations during northward interplanetary magnetic field
}

\author{
Chao-Song Huang, G J Sofko, V A Koustov, J W Macdougall, R A
} Greenwald, J J Ruohoniemi, Jean-Pierre J Villain, M M Lester, J.

Watermann, V O Papitashvili, et al.

\section{To cite this version:}

Chao-Song Huang, G J Sofko, V A Koustov, J W Macdougall, R A Greenwald, et al.. Long-period magnetospheric-ionospheric perturbations during northward interplanetary magnetic field. Journal of Geophysical Research Space Physics, 2001, 106 (A7), pp.91-104. 10.1029/2000JA900192 . insu01558983

\section{HAL Id: insu-01558983 \\ https://hal-insu.archives-ouvertes.fr/insu-01558983}

Submitted on 10 Jul 2017

HAL is a multi-disciplinary open access archive for the deposit and dissemination of scientific research documents, whether they are published or not. The documents may come from teaching and research institutions in France or abroad, or from public or private research centers.
L'archive ouverte pluridisciplinaire HAL, est destinée au dépôt et à la diffusion de documents scientifiques de niveau recherche, publiés ou non, émanant des établissements d'enseignement et de recherche français ou étrangers, des laboratoires publics ou privés. 


\title{
Long-period magnetospheric-ionospheric perturbations during northward interplanetary magnetic field
}

\author{
Chao-Song Huang, ${ }^{1,2}$ G. J. Sofko, ${ }^{1}$ A. V. Koustov, ${ }^{1}$ J. W. MacDougall, ${ }^{3}$ \\ R. A. Greenwald, ${ }^{4}$ J. M. Ruohoniemi, ${ }^{4}$ J. P. Villain, ${ }^{5}$ M. Lester, ${ }^{6}$ \\ J. Watermann, ${ }^{7}$ V. O. Papitashvili, ${ }^{8}$ and W. J. Hughes ${ }^{9}$
}

\begin{abstract}
In this paper we present observations of long-period magnetospheric-ionospheric perturbations during northward interplanetary magnetic field (IMF). On November 10-11, 1998, the IMF was northward for 29 hours. The solar wind and IMF parameters were relatively steady. After the IMF had been northward for 14 hours, strong ionospheric velocity (or electric field) perturbations were observed by the Iceland West HF radar in the postmidnight/dawn sector. The velocity perturbations showed periods in the range $50-60 \mathrm{~min}$, with a mean value $\sim 54 \mathrm{~min}$. The Super Dual Auroral Radar Network observed periodic changes of nightside ionospheric convection. For each cycle a large-scale convection cell formed around 0200 magnetic local time (MLT) near magnetic latitude $70^{\circ}$ and grew for $\sim 30 \mathrm{~min}$. The convection cell then moved eastward with a mean velocity of $\sim 1.4 \mathrm{~km} \mathrm{~s}^{-1}$. The final position of the cell focus was around $0600 \mathrm{MLT}$ near magnetic latitude $77^{\circ}$. Ground magnetometers recorded weak magnetic perturbations with periods 50-60 min in both the premidnight and postmidnight sectors. The GOES 8 satellite also observed magnetospheric magnetic field perturbations with similar periods at $L \sim 6$ on the nightside. The satellite and the key radars which observed the convection oscillations are nearly magnetically conjugate, so the good temporal correlation between the satellite and radar data indicates that the magnetospheric and ionospheric perturbations have a common source. We propose that the magnetospheric-ionospheric perturbations originated within the magnetosphere. The transformation of the magnetospheric tail from an extended to a more dipolar shape during northward IMF is associated with $40-60 \mathrm{~min}$ period global tail oscillations which ultimately result in the generation of field-aligned currents and nightside ionospheric convection vortices near $X=-10 R_{E}$. If the proposed mechanism is correct, it will be possible to infer the magnetospheric cavity shape from the measured periodicity of the tail oscillations during northward IMF.
\end{abstract}

\section{Introduction}

The Earth's magnetosphere can support a variety of oscillations with a very large spread of periods, including long periods of about 1 hour. Quasiperiodic recurrence of magnetospheric substorms has been observed during southward interplanetary magnetic field (IMF). Borovsky et al. [1993] determined the time interval between consecutive substorm onsets from particle injection events monitored on

\footnotetext{
${ }^{1}$ Institute of Space and Atmospheric Studies, University of Saskatchewan, Saskatoon, Saskatchewan, Canada.

${ }^{2}$ Now at Haystack Observatory, Massachusetts Institute of Technology, Westford, Massachusetts.

${ }^{3}$ Department of Electrical Engineering, University of Western Ontario, London, Ontario, Canada.

${ }^{4}$ Applied Physics Laboratory, Johns Hopkins University, Laurel, Maryland.

${ }^{5}$ Laboratoire de Physique et Chemie de l'Environnement, Centre National de la Recherche Scientifique, Orléans, France.

${ }^{6}$ Department of Physics and Astronomy, University of Leicester, Leicester, England, United Kingdom.

${ }^{7}$ Danish Meteorological Institute, Copenhagen, Denmark.

${ }^{8}$ Space Physics Research Laboratory, University of Michigan, Ann Arbor, Michigan.

${ }^{9}$ Center for Space Physics, Boston University, Boston, Massachusetts.
}

Copyright 2001 by the American Geophysical Union.

Paper number 2000JA900192.

0148-0227/01/ 2000JA900192\$09.00 geosynchronous satellites. They found that the most probable time between substorm onsets was -2.75 hours; this was interpreted to be the period between substorms when the IMF remains southward for extended periods of times so that the driving of the magnetosphere is uninterrupted. Farrugia et al. [1993] studied substorm activity during the passage of an interplanetary magnetic cloud during which the IMF was southward for approximately 18 hours. In total, 23 substorm onsets were identified during this period. The onsets were fairly evenly distributed with an average recurrence frequency of one substorm every $\sim 50 \mathrm{~min}$; the shortest interval between substorms was $\sim 25 \mathrm{~min}$ and the longest was $100 \mathrm{~min}$. Klimas et al. [1994] studied substorm recurrence with a Faraday loop model. Given a steady loading rate from the solar wind, the model showed that substorms are activated with a recurrence time of $\sim 1$ hour, which is interpreted to be a natural unloading period in the magnetospheric dynamics. Siscoe et al. [1994] and Shodhan et al. [1996] presented Geotail observations of long-period ( 100 min) oscillations in plasma density and velocity between magnetosheath-like and lobe-like values. They suggested that these oscillations were measured when the tail boundary moved back and forth over the satellite. The boundary oscillations might be caused by the expansions and contractions of the crosssectional area of the tail during substorms; this internally driven motion was termed "breathing."

Long-period fluctuations have been observed in both the magnetosphere and the ionosphere. Chen and Kivelson [1991] 
studied ultralow frequency waves in the lobes of the magnetotail and found fluctuations of magnetic field with a nominal period of $\sim 35$ min. Rinnert [1996] found quasiperiodic enhancements of electron density in the auroral $E$ region in the European Incoherent Scatter (EISCAT) radar data. The periods were typically 40-60 min. These events could occur at all local times of day with a maximum probability in the morning sector. Lessard et al. [1999] presented ground and satellite observations of monochromatic (1-2 min) magnetic pulsations, spanning more than 8 hours in local time and from $L=5.9$ to $L=9.6$. The pulsations were modulated with a $45-\mathrm{min}$ periodicity. It is not clear whether these long-period fluctuations were caused by fluctuations in the solar wind/IMF or by some processes intrinsic to the magnetosphere.

Huang et al. [2000a] recently reported quasiperiodic ionospheric disturbances that occurred during northward IMF. After the IMF turned northward several hours, ground magnetometer magnetic deviations with a periodicity of $\sim 40 \mathrm{~min}$ were observed in the magnetic latitude range $74^{\circ}-80^{\circ}$ over an extended longitudinal region in the morning sector. The highlatitude oscillating currents were closely associated with the generation of gravity waves with similar periods; these were observed by HF radars at lower latitudes. The solar wind and IMF were relatively stable; there were no obvious source perturbations in the upstream solar wind for the ionospheric disturbances. They suggested that the source of the long-period ionospheric disturbances might be within the magnetosphere. Since the magnetic deviations recorded with ground magnetometers were quite weak (an amplitude of $\sim 10 \mathrm{nT}$ ), it was not possible to determine from the magnetometer record whether the disturbances traveled along some specific direction and whether the ionospheric convection showed corresponding changes.

In this paper, we present HF radar, ground magnetometer, and satellite observations of magnetospheric-ionospheric perturbations with periods 50-60 min within a 29-hour interval of northward IMF. We will study the quasiperiodic changes of global convection and discuss the mechanism responsible for the perturbations.

\section{Observations}

We study an event that occurred on November 11, 1998. Figure la shows the IMF $B_{z}$ component and 3-hour $K p$ index on November 10-11. $B_{z}$ became positive at 1300 UT on November 10 and remained positive for 29 hours. After 0600 UT on November 10 , the $K p$ index was smaller than 2 for the rest of the

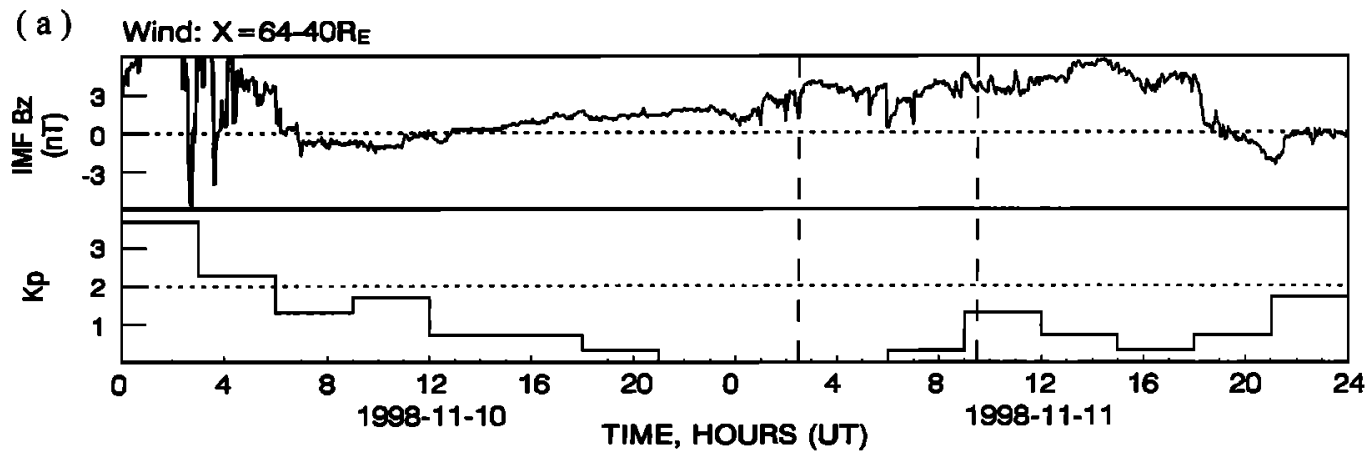

(b) Wind: $X=49 R_{E}, Y=17 R_{E}, Z=-3 R_{E}$

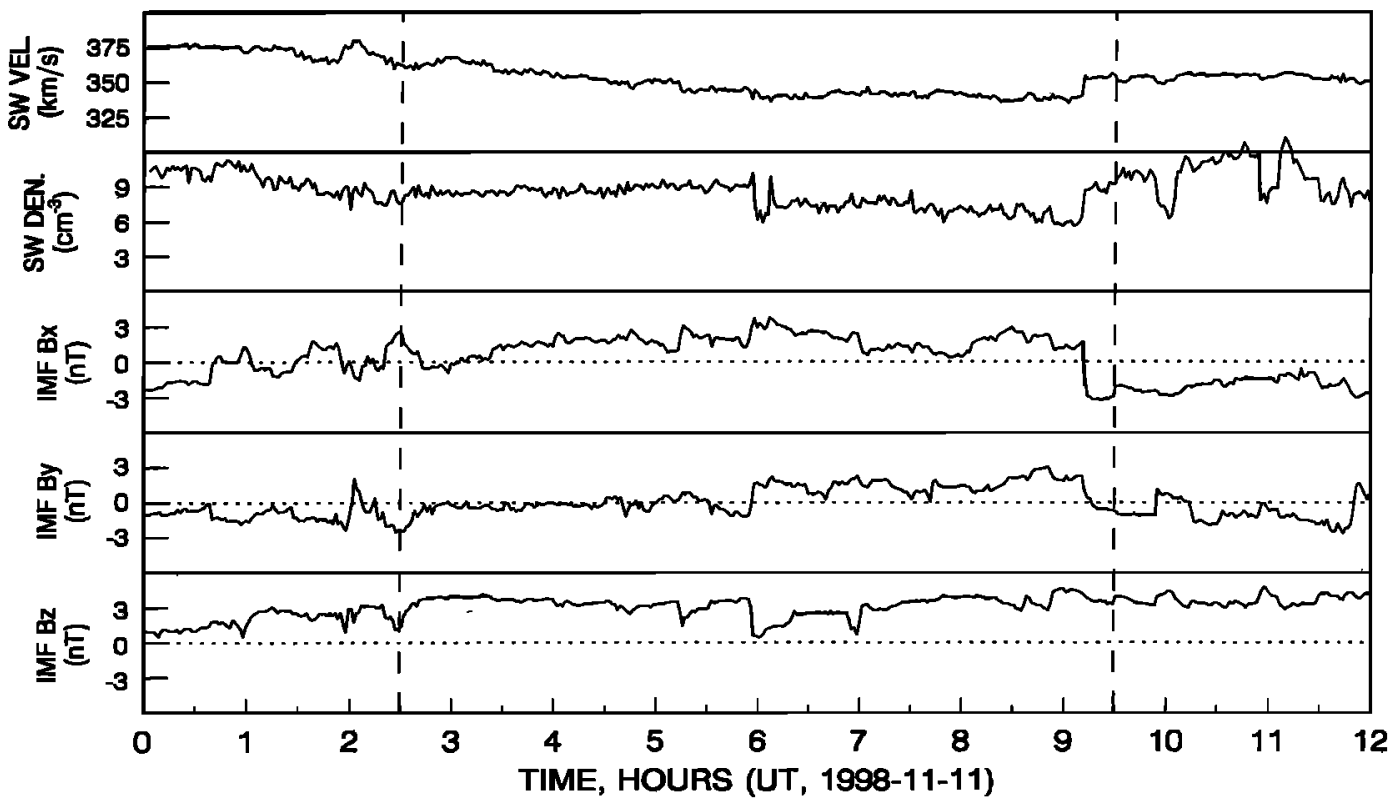

Figure 1. Solar wind and interplanetary magnetic field data observed by the Wind spacecraft on November 10-11, 1998. 
2-day interval. The $X$ distance of the Wind satellite varied from 64 to $40 R_{E}$ during the 2 days. We are interested in the interval 0230-0930 UT on November 11, indicated by the vertical dashed lines. Figure $1 \mathrm{~b}$ shows the solar wind velocity, solar wind density, and IMF components observed with Wind at about $X_{\mathrm{gsm}}=49 R_{E}$ during $0000-1200 \mathrm{UT}$ on November 11 . All the parameters were relatively stable, although some fluctuations occurred. Between 0230 and 0930 UT on November 11, $B_{\lambda}$ was positive, $B_{y}$ varied from nearly zero to weakly positive, and $B_{2}$ was positive and was the largest component (3-4 nT) except for the decreases near 0600 and 0700 UT. We used the radar data to determine the IMF propagation delay. As shown in Figure la, the IMF $B_{z}$ component changed from positive $(\sim 4 \mathrm{nT})$ to nearly zero at 1820 UT on November 11. Sudden changes in the $F$ region plasma velocities were observed to occur near 1850 UT by the Saskatoon HF radar (the radar velocity plot is not shown). The total time delay would include about $10-15 \mathrm{~min}$ for the IMF to travel from Wind to the bow shock, 6-8 min to travel through the magnetosheath, and $\sim 10 \mathrm{~min}$ for the ionospheric response to the IMF arrival at the magnetopause. Note that the total delay is determined from the radar data; the detailed times of the IMF propagation between the Wind position and bow shock and between the bow shock and magnetopause are not important for our purpose. An uncertainty of $10 \mathrm{~min}$ in the time delay will not significantly affect our analysis because an interval of 7 hours is considered. With this 30 -min delay, the IMF at the Wind position between 0230 and 0930 UT would influence the ionospheric convection between 0300 and 1000 UT. During this interval the $K p$ index was 0 for 0300-0600 UT, $0+$ for 0600-0900 UT, and $1+$ for 0900-1200 UT, confirming that the interval was magnetically quiet.

Plate 1 displays the line-of-sight component of the Doppler velocities measured by the Iceland West $\mathrm{HF}$ radar $\left(63.9^{\circ} \mathrm{N}, 22^{\circ} \mathrm{W}\right.$, geographic) during 0300-1000 UT on November 11, 1998. Magnetic local time (MLT) at the radar site is approximately equal to the universal time (UT). The velocity perturbations are observed in the postmidnight/morning sector. The radar echoes are from the $F$ region; the line-of-sight Doppler velocities represent the $F$ region plasma convection component along the radar beam. In Plate 1a the negative velocities (yellow) represent plasma motion away from the radar; the positive velocities (blue) represent plasma motion toward the radar. Seven cycles (yellow bands or blue bands) of velocity oscillations can be clearly identified, with periods 50-60 min. Since there are some gaps in the data from individual radar beams, the velocity data taken from beams 8 and 9 at range $1665 \mathrm{~km}$ are used in Plate $1 \mathrm{~b}$ to show the temporal variations. It is clear that the velocities show quasiperiodic perturbations with periods $50-60 \mathrm{~min}$. A cosine wave with a period of $54 \mathrm{~min}$ is superposed on the velocity data and approximately coincides with the velocity variations, showing that the velocity perturbations have a mean periodicity of $\sim 54 \mathrm{~min}$. From Plate $1 \mathrm{~b}$ the amplitude of the velocity perturbations is $\sim 500 \mathrm{~m} \mathrm{~s}^{-1}$. If we take the geomagnetic field to be $6 \times 10^{-5} \mathrm{~T}$ in the auroral ionosphere, the amplitude of the corresponding electric field perturbations is $-30 \mathrm{mV} \mathrm{m}^{-1}$. As mentioned above, Plate 1 shows only the line-of-sight velocities. The real ionospheric convection velocities and, in turn, the electric field perturbations, could be larger.

To study the ionospheric convection oscillations, we use data from six HF radars of the Super Dual Auroral Radar Network (SuperDARN) [Greenwald et al., 1995] in the Northern Hemisphere. The names and locations of these radars are listed in Table 1. In general, each radar pair has a maximum possible common field of view of about $4 \times 10^{6} \mathrm{~km}^{2}$. Within this target region there are in principle 256 intersection points between the 16 beams of each radar. In practice, there are not usually line-ofsight data from both radars at all these intersection points, because that would require that both the propagation and the scattering conditions be favorable for each of the radars. Therefore the field of view in general contains three classes of intersection points, those with data from both radars, those with data from one radar only, and those with no data. The radar data are used as the inputs for a spherical harmonic type of expansion [Ruohontemi and Baker, 1998] of the global convection (or electric potential, since the equipotential surfaces are convection streamlines). Wherever there is a region in which data exist at a number of points from at least one radar, the above expansion is strongly constrained, and full velocity vectors can be derived. These regions are easily identified on the convection plots such as Figures 2 and 3 , because the vectors are plotted as line segments with a dot at the base. Only where there is measured radar data are such convection vectors shown. The convection vectors (and potential contours) near such regions are expected to be reasonably accurate. In the present paper, we confine our discussions to such regions only. Away from the regions where the radar measurements are available, a statistical model [Ruohoniemi and Greenwald, 1996] is used to complete the global potential pattern, but as noted by the above authors, considerable discretion should be used in interpreting such contours. The nominal points of highest and lowest potential are marked with a plus and a cross, respectively, and are used to estimate the cross-polar cap potential, written near the bottom right corner of each map (as in Figures 2 and 3). The dayside convection could be very structured and appeared as multicell patterns for northward IMF, as observed at later times on the

Table 1. Locations of Radars and Ground Magnetometers

\begin{tabular}{|c|c|c|c|c|c|}
\hline \multirow[t]{2}{*}{ Stations } & \multirow[t]{2}{*}{ Abbreviation } & \multicolumn{2}{|c|}{ Geographic } & \multicolumn{2}{|c|}{ Magnetic } \\
\hline & & Lat. & Lon. & Lat. & Lon. \\
\hline \multicolumn{6}{|c|}{ SuperDARN HF Radars } \\
\hline Hankasalmi & $\mathbf{F}$ & 62.3 & 26.6 & 56.4 & 103.0 \\
\hline Pykkvibaer & $\mathbf{E}$ & 63.9 & 340.8 & 65.0 & 68.6 \\
\hline Stokkseyri & $\mathbf{W}$ & 63.9 & 338.0 & 65.0 & 68.6 \\
\hline Goose Bay & G & 53.3 & 299.5 & 63.2 & 22.6 \\
\hline Kapuskasing & $\mathbf{K}$ & 49.4 & 277.7 & 61.6 & 11.1 \\
\hline Saskatoon & $\mathrm{T}$ & 52.2 & 253.5 & 61.3 & 313.6 \\
\hline \multicolumn{6}{|c|}{ CANOPUS Magnetometers } \\
\hline Eskimo Point & ESKI & 61.1 & 265.9 & 71.9 & 328.4 \\
\hline Fort Churchill & FCHU & 58.8 & 265.9 & 69.7 & 329.2 \\
\hline Gillam & GILL & 56.4 & 265.4 & 67.4 & 329.1 \\
\hline Island Lake & ISLL & 53.9 & 265.3 & 64.9 & 329.7 \\
\hline \multicolumn{6}{|c|}{ MACCS Magnetometers } \\
\hline Gjoa Haven & GH & 68.6 & 264.1 & 78.2 & 323.4 \\
\hline Baker Lake & BL & 64.3 & 264.0 & 74.3 & 326.1 \\
\hline \multicolumn{6}{|c|}{ Greenland Magnetometers } \\
\hline Uummannaq & UMQ & 70.7 & 307.9 & 77.1 & 44.2 \\
\hline Attu & ATU & 67.9 & 306.4 & 74.8 & 39.1 \\
\hline Kangerlussuaq & STF & 67.0 & 309.3 & 73.4 & 41.8 \\
\hline Nuuk & GHB & 64.2 & 308.3 & 70.8 & 38.6 \\
\hline Paamiut & FHB & 62.0 & 310.3 & 68.3 & 39.6 \\
\hline Narssarssuaq & NAQ & 61.2 & 314.6 & 66.6 & 43.9 \\
\hline Magic Gisp & MCG & 72.6 & 321.6 & 76.5 & 62.4 \\
\hline Daneborg & DNB & 74.3 & 339.8 & 75.3 & 81.1 \\
\hline
\end{tabular}


(a)

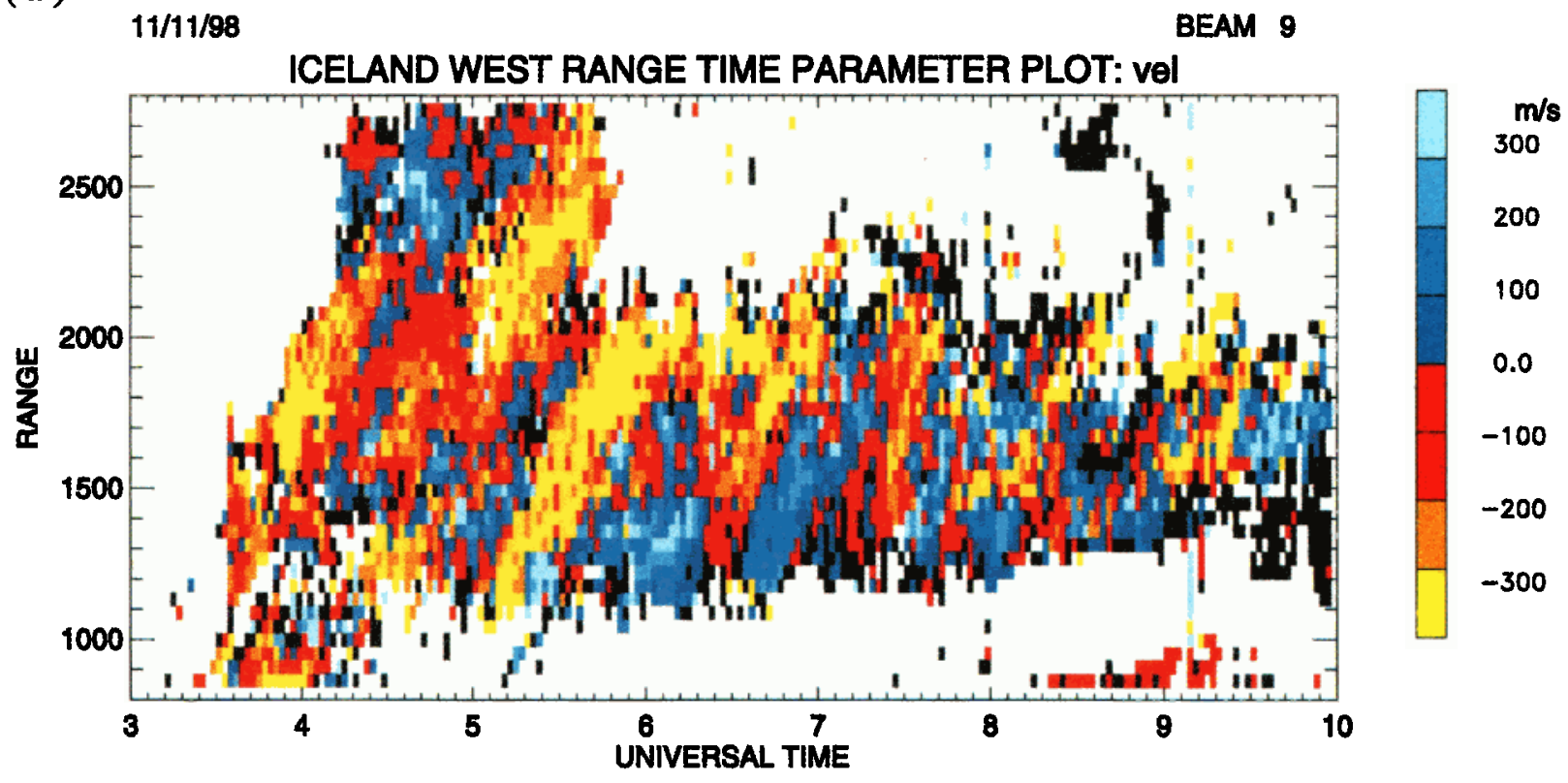

(b)

Ground Scatter

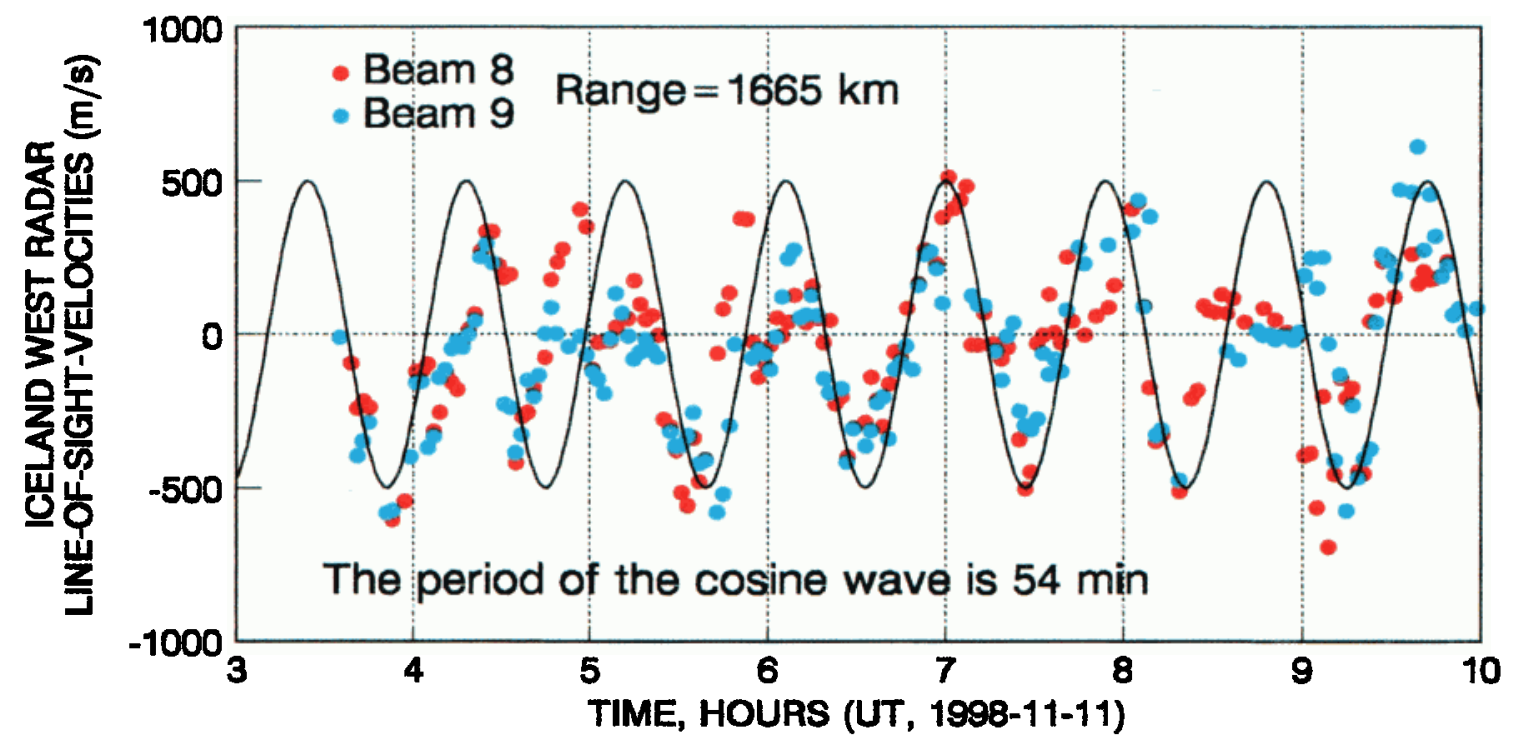

Plate 1. (a) The line-of-sight velocities measured by the Iceland West HF radar beam 9 between 0300 and 1000 UT on November 11, 1998, plotted as a function of range (in kilometers) and time. (b) The line-of-sight velocities from beams 8 and 9. Magnetic local time at the radar site is approximately equal to UT. 
(a)

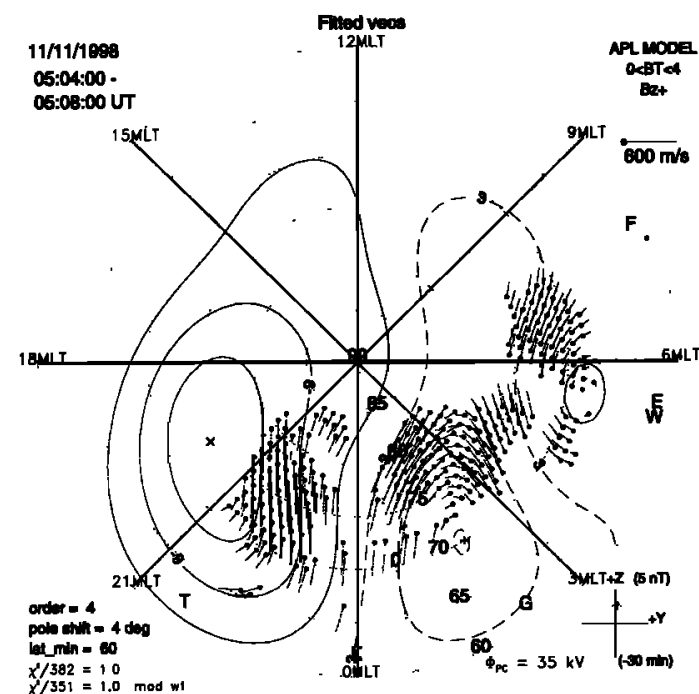

(c)

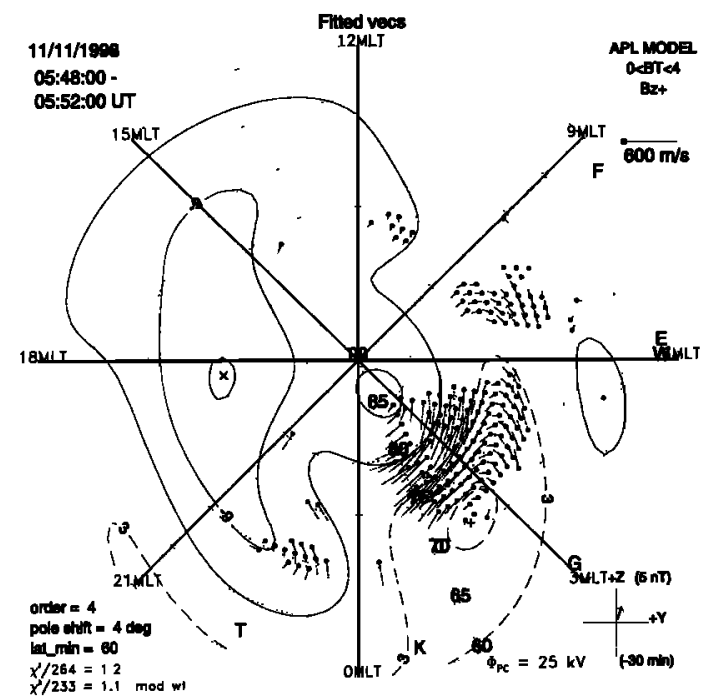

(b)

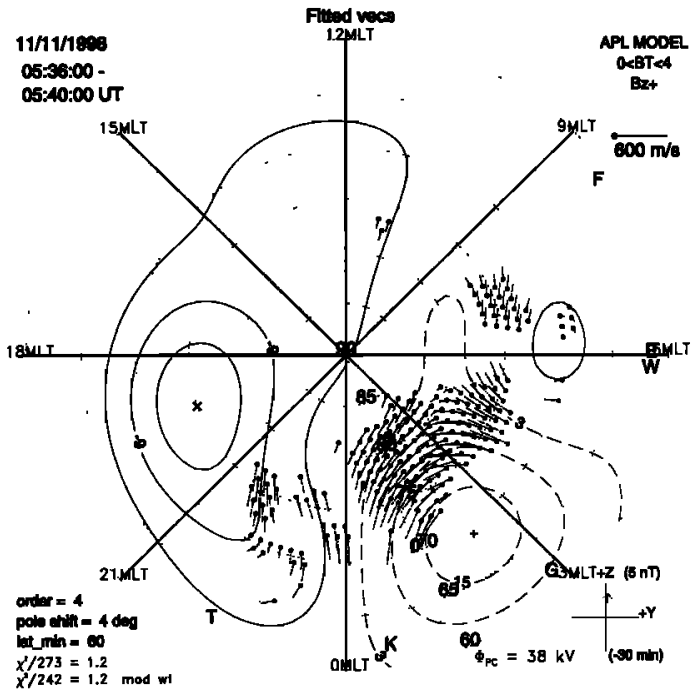

(d)

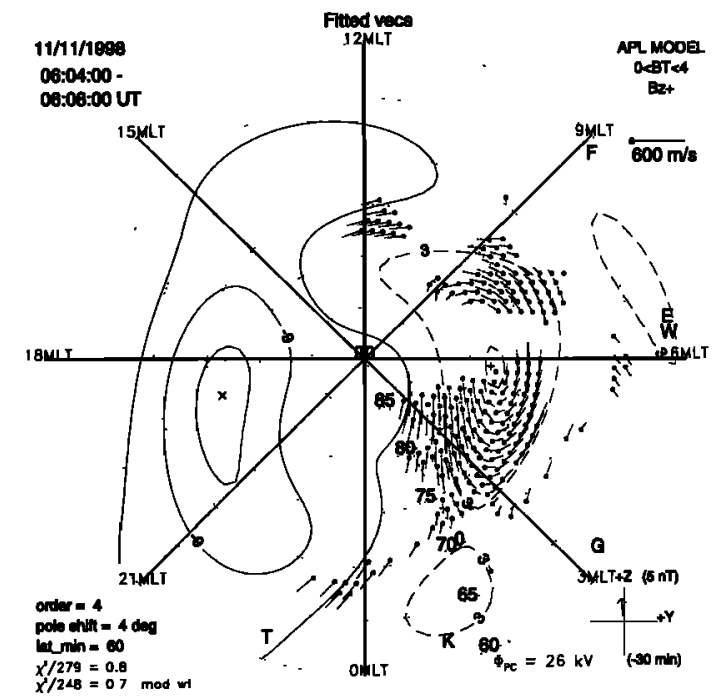

Figure 2. Ionospheric convection plots observed with the SuperDARN HF radars in the Northern Hemisphere between 0504 and 0608 UT on November 11, 1998. The radar positions are indicated by capital letters: T, Saskatoon; K, Kapuskasing; G. Goose Bay; W, Stokkseyri (also termed Iceland West); E, Pykkvibaer (also termed Iceland East); F, Hankasalmi, Finland.

same day [Huang et al., 2000b]. This paper focuses only on the nightside oscillations and does not include the simultaneous variations in the dayside convection.

Plate 1 shows the seven cycles of the ionospheric line-of-sight Doppler velocity perturbations. The two-dimensional ionospheric convection pattern derived from all the Northern Hemisphere radars shows corresponding quasiperiodic changes. We first present the convection plots for one cycle, as shown in Figure 2. The radar data are averaged over $4 \mathrm{~min}$ (two radar scans) for each plot. The IMF orientation in the $Y-Z$ plane is illustrated on the bottom right corner of each plot, with the inferred 30-min delay. In Figure $2 a$ the meridional component of the ionospheric flow is poleward between 0300 and 0600 MLT and becomes equatorward between 0000 and 0300 MLT. The high-latitude counterclockwise flow must be closed at lower latitudes; Figure $2 \mathrm{~d}$ indeed shows such flow closure between magnetic latitudes $70^{\circ}$ and $75^{\circ}$. It is reasonable to assume that a counterclockwise convection cell exists in the postmidnight/dawn sector, although the radar data do not show the complete structure of the cell. At the beginning of each cycle the cell starts to form, centered around $0200 \mathrm{MLT}$ near magnetic latitude $70^{\circ}$, as shown for 0504 UT in Figure 2a. The location of the cell remains almost unchanged for $\sim 30 \mathrm{~min}$, as shown for $0536 \mathrm{UT}$ in Figure $2 \mathrm{~b}$. However, the flow associated with the cell intensifies between 0504 and 0536 UT. The cell then begins to move eastward, as shown in Figure 2c at 0548 UT. Finally, at 0604 UT the cell focus is located around 0600 MLT near magnetic latitude $78^{\circ}$, as shown in Figure 2d. The shift of the cell focus from 0200 to 0600 MLT takes $\sim 20 \mathrm{~min}$, which corresponds to a mean eastward velocity of $\sim 1.4 \mathrm{~km} \mathrm{~s}^{-1}$ for the cell focus.

The changes of the ionospheric convection pattern are similar for all the seven cycles. Figure 3 shows the convection plots for three cycles. In the left column of Figure 3 the counterclockwise convection cell is focused between 0200 and 0300 MLT near magnetic latitude $70^{\circ}$; this corresponds to the time of the flow intensification for each cycle, as defined above. In the right column the cell focus is located between 0500 and 0600 MLT in the magnetic latitude range $75^{\circ}-80^{\circ}$; this represents the final 
(a)

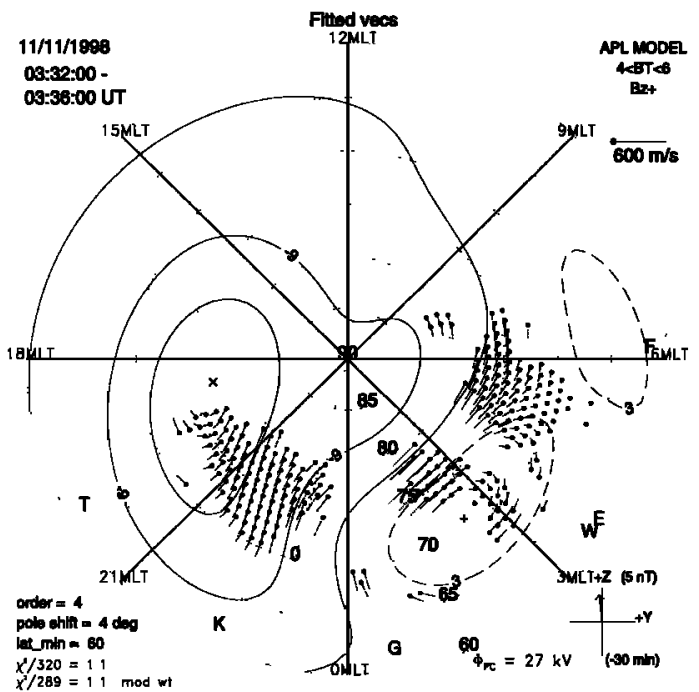

(c)

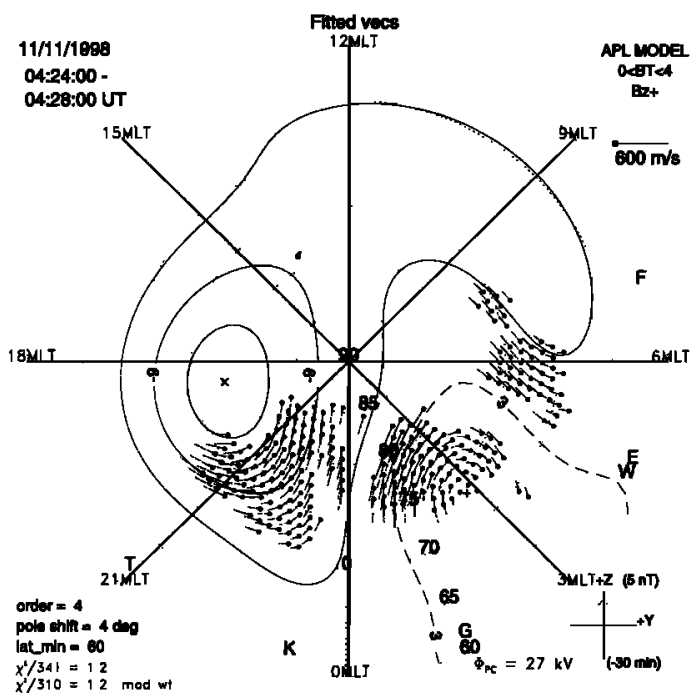

(e)

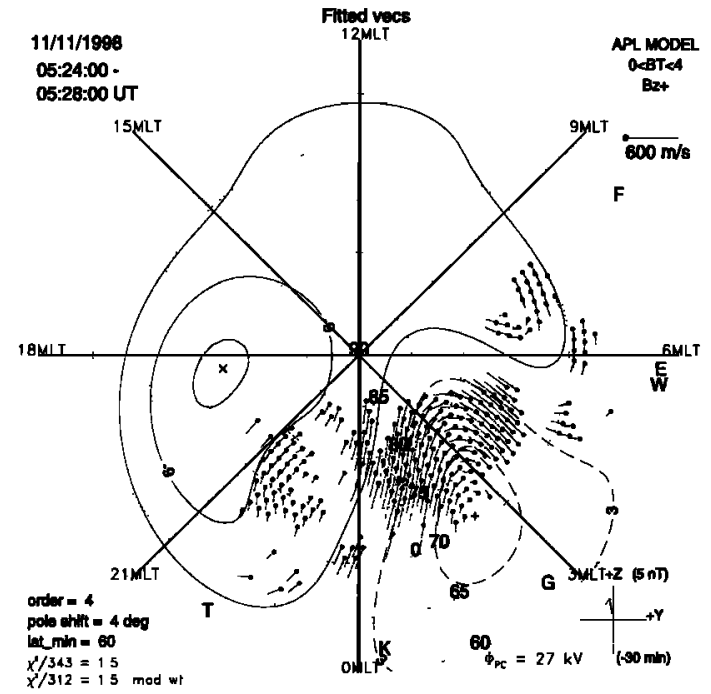

(b)

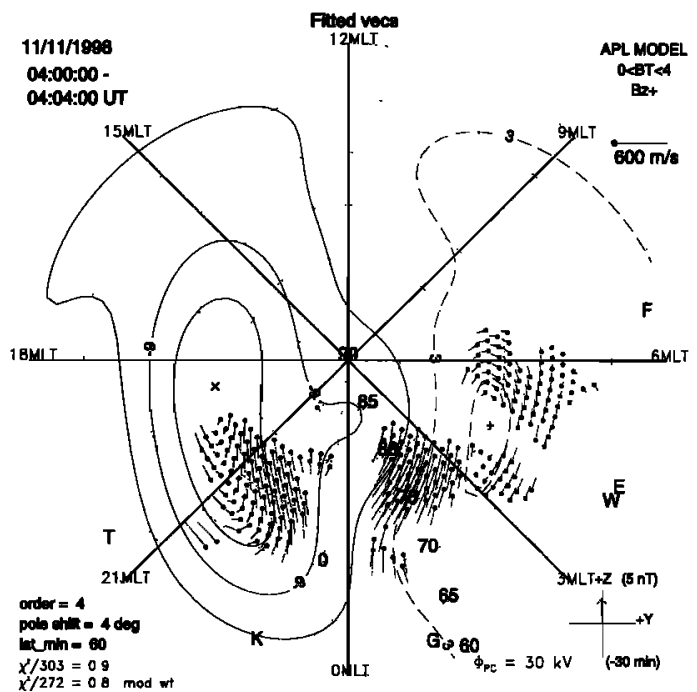

(d)

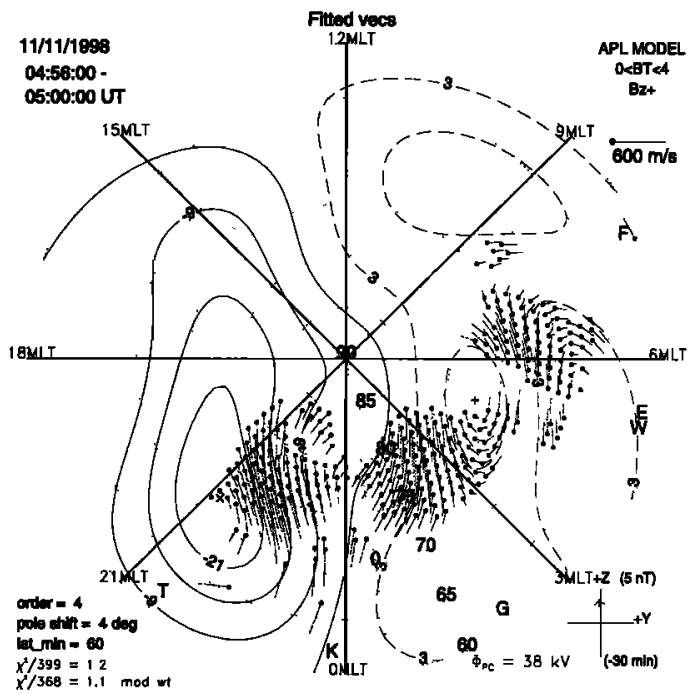

(f)

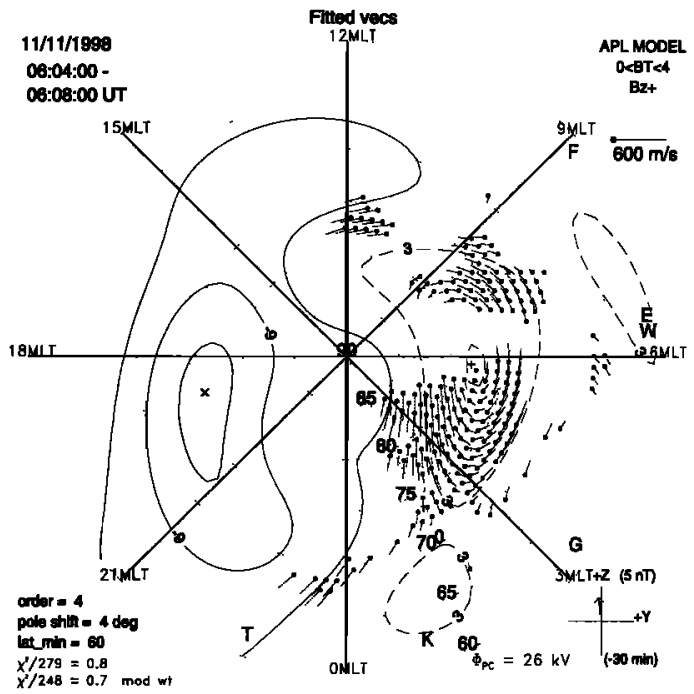

Figure 3. Same as Figure 2, but for six different times.

position of the cell for each cycle. The convection in the premidnight/dusk sector is not as clear because of the lack of data there. Our analysis will be confined to the convection in the postmidnight/dawn sector only. For each cycle a counterclockwise convection cell forms around 0200 MLT near magnetic latitude $70^{\circ}$, intensifies for $\sim 30 \mathrm{~min}$, takes $\sim 20 \mathrm{~min}$ to move eastward, and is finally focused around 0600 MLT near magnetic latitude $77^{\circ}$. 
( a )

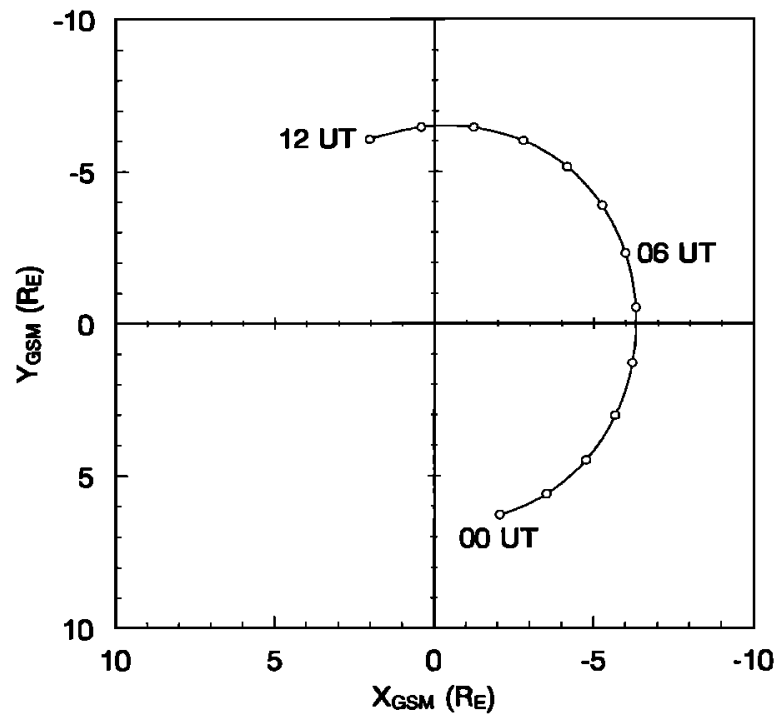

(b)

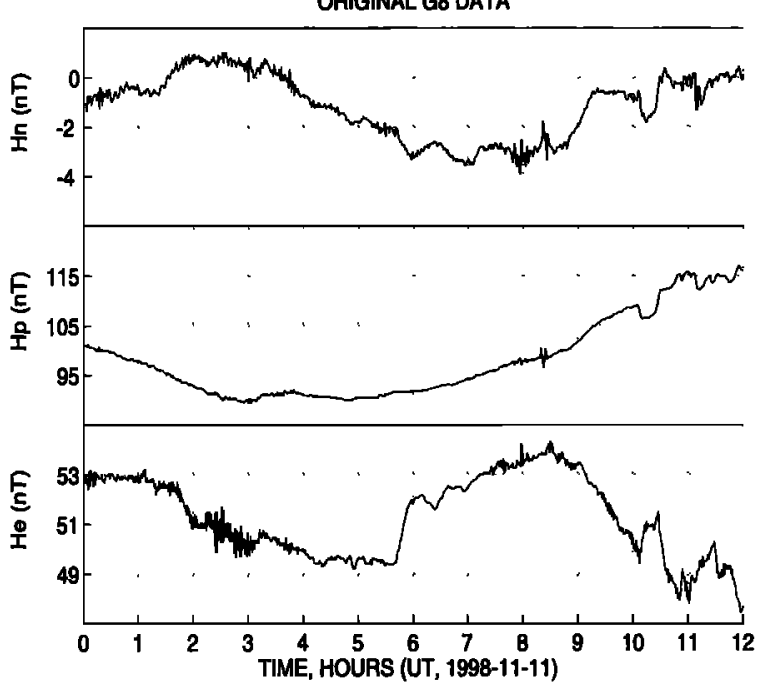

(c)

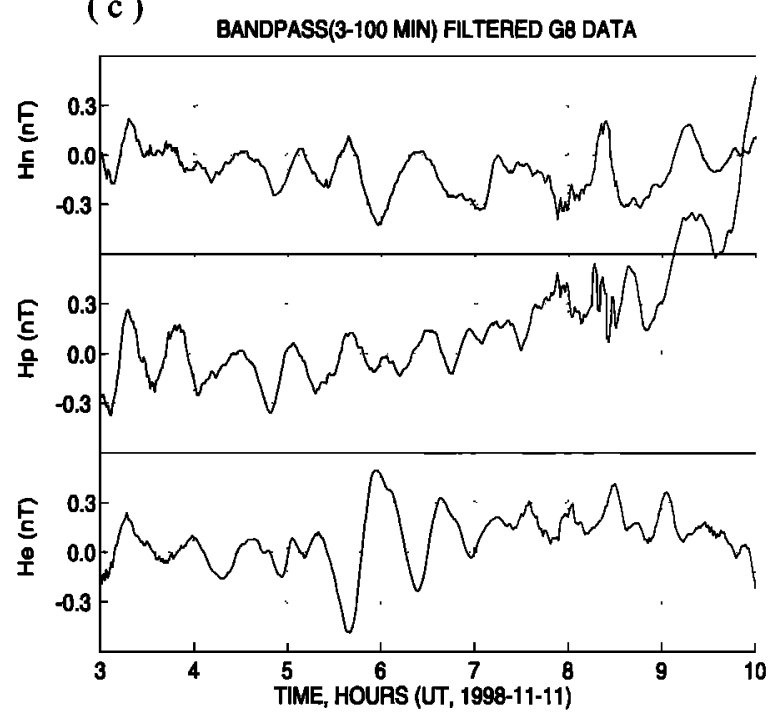

Figure 4. (a) The GOES 8 satellite orbit in the equatorial plane during 0000-1200 UT on November 11, 1998, (b) the geomagnetic field components measured by GOES 8, and (c) the band-pass (3-100 min) filtered data of the geomagnetic field.

We now take a look at the measurements of the Geostationary Operational Environmental Satellite GOES 8. Figure 4a shows the orbit of GOES 8 in the equatorial plane during 0000-1200 UT on November 11, 1998; the distance in the $Z$ coordinate was small $\left(<2 R_{E}\right.$ ). During the period of interest, GOES 8 was on the nightside. Figure $4 \mathrm{~b}$ shows the geomagnetic field components measured with the magnetometer on the satellite. The vector magnetic field is given as $1-\mathrm{min}$ averaged values in the local coordinate system. The magnetic field component $H_{p}$ is perpendicular to the satellite orbital plane or parallel to the Earth's spin axis in the case of a zero degree inclination orbit, $H_{e}$ is perpendicular to $H_{p}$ and directed earthward, and $H_{n}$ is perpendicular to both $H_{p}$ and $H_{e}$ and is directed eastward. It is clear that $H_{n}$ shows perturbations with a periodicity of 50-60 min superposed on the half-day variations. The $H_{p}$ component is the strongest; it is difficult to see small perturbations superposed on it. The $H_{e}$ component also shows some perturbations.

In order to identify the perturbations which are of interest, we apply a band-pass filter (3-100 $\mathrm{min})$ to the GOES 8 data to remove the half-day variations. Since the quasiperiodic perturbations in the radar velocity occur between 0300 and 1000 UT (Plate 1), the filtered GOES 8 data are also given for this interval, as shown in Figure 4c. Between 0300 and 0700 UT, the $H_{n}$ and $H_{\rho}$ perturbations are almost in phase; the $H_{e}$ perturbations appear to have a phase delay. After 0700 UT the $H_{p}$ and $H_{n}$ components show some shorter-period perturbations. We will not discuss the relationship among the three components in detail. The important result for our purpose is that the magnetospheric magnetic field shows perturbations with periods similar to the ionospheric velocity (or electric field) perturbations.

We compare the measurements of the magnetospheric magnetic field perturbations and the ionospheric electric field perturbations. Figure 5 shows the comparison between the Doppler velocities measured by the Iceland West radar beams 8 and 9 at range $1665 \mathrm{~km}$ and the filtered $H_{n}$ component. In Figure 5 the GOES $8 H_{n}$ is inverted with positive values at the bottom and negative values at the top. There happens to be a phase difference of about 180 degrees between the ionospheric velocity 


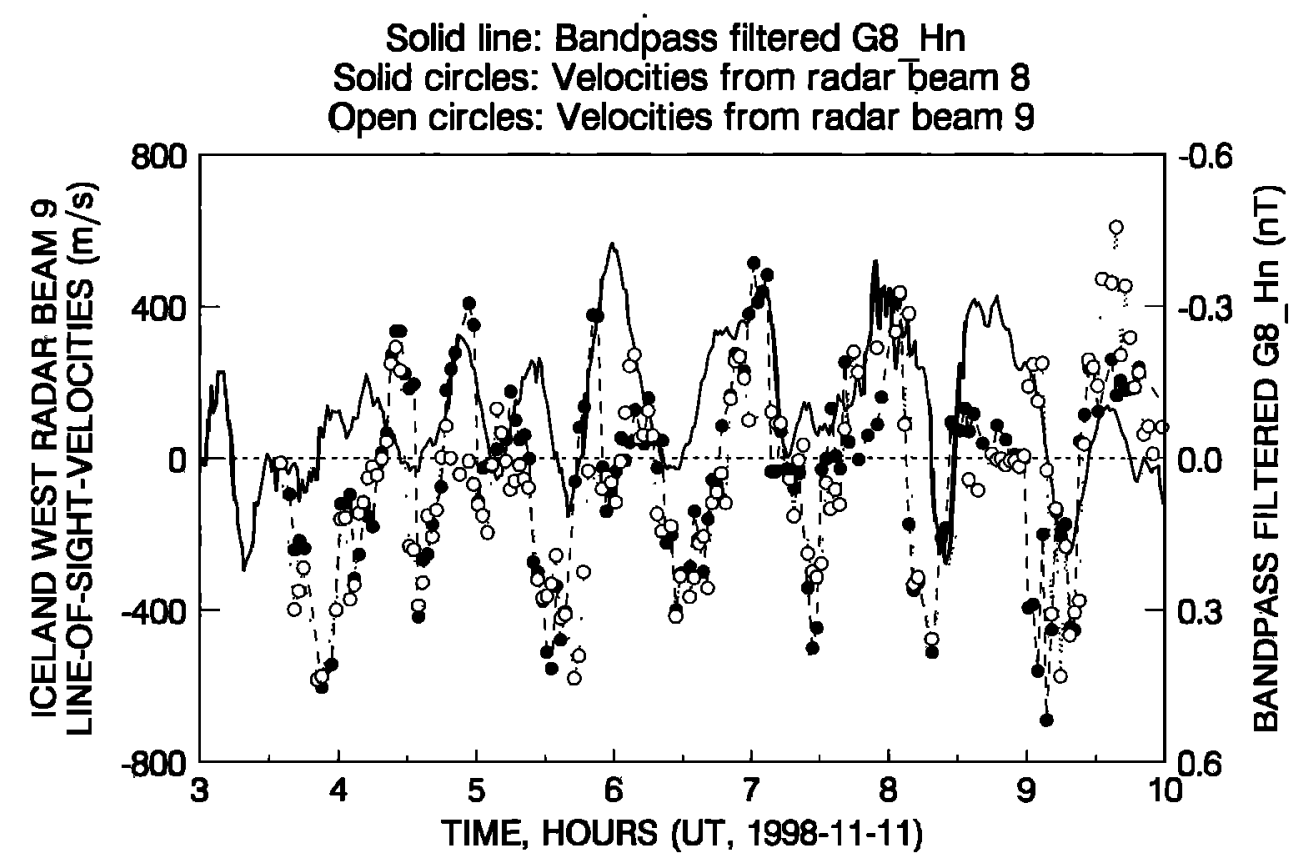

Figure 5. Comparison between the magnetospheric magnetic field perturbations measured by GOES 8 and the ionospheric Doppler velocity perturbations measured by the Iceland West radar. Solid line, band-pass filtered GOES $8 H_{n}$; solid circles, velocity from radar beam 8; open circles, velocity from radar beam 9 .

and $H_{n}$, but this is not of any particular significance because of the difference in latitude and longitude between the radar observation points and the conjugate point to the GOES 8 satellite. The important result is that for the entire interval of about 7 hours the radar and satellite data exhibit similar temporal fluctuations. The coincidence between the satellite and radar data implies that the magnetospheric perturbations observed by the satellite and the ionospheric perturbations observed by the radar have a common source.

(a)

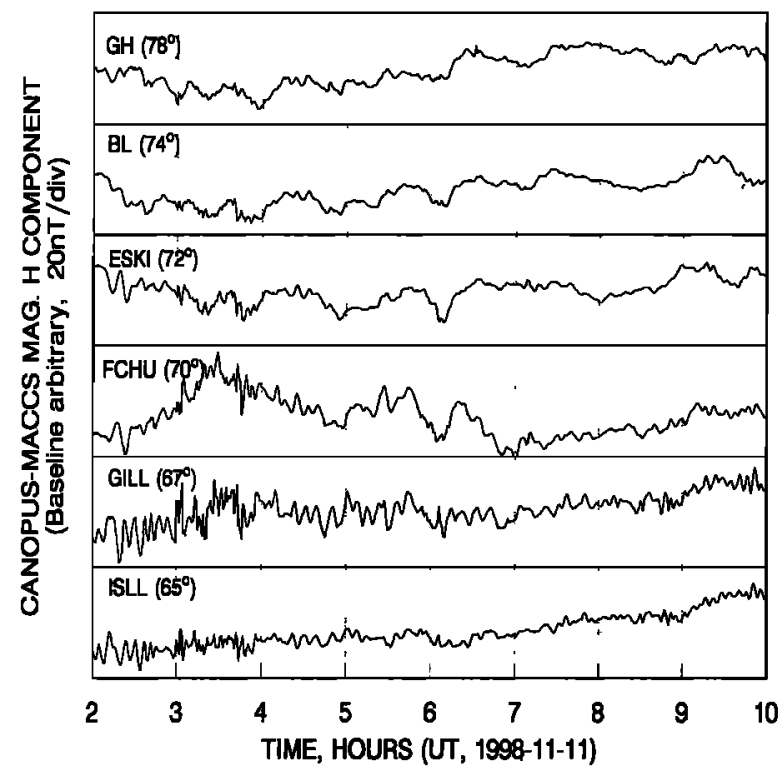

The ionospheric velocity perturbations shown in Plate 1 represent perturbations in ionospheric electric field which can cause corresponding perturbations in ionospheric currents, detected as magnetic fluctuations by ground-based magnetometers. Figure 6 shows the $H$ (northward) component of the magnetic perturbations recorded with the Canadian Auroral Network for the OPEN Program Unified Study (CANOPUS), Magnetometer Array for Cusp and Cleft Studies (MACCS), and Greenland West Coast magnetometer chains on November 11,

Figure 6. The $H$ component of magnetic deviations recorded by the CANOPUS-MACCS and Greenland West Coast magnetometer chains during 0200-1000 on November 11, 1998. Geomagnetic latitude for each station is given in the figure. 
1998. The locations of the magnetometer stations are given in Table 1. The magnetic local time at the CANOPUS and MACCS chains is approximately UT minus 7 hours, while for the Greenland West Coast chain it is approximately UT minus 2 hours. For the interval 0200-1000 UT shown in Figure 6 the local time is approximately $1900-0300 \mathrm{MLT}$ at the CANOPUS and MACCS chains and 0000-0800 MLT at the Greenland chain. Therefore these magnetometer chains recorded the magnetic perturbations in the premidnight and postmidnight sectors, respectively. The magnetic perturbations are quite weak $(\sim 5 \mathrm{nT})$, possibly caused by weak conductivity in the quiet nightside ionosphere. The perturbations at higher latitudes (GH, BL, UMQ, and ATU) appear to have a periodicity of $\sim 1$ hour. This result is expected on the basis of the ionospheric screening effect [Hughes and Southwood, 1976a, 1976b] in which the magnetospheric hydromagnetic wave magnetic perturbations seen on GOES 8 in the eastward component $H_{n}$ are, as a result of the ionospheric Hall currents resulting from the electric field of these hydromagnetic waves, rotated by 90 degrees and seen best in the northward $H$ component of the magnetometers on the ground. An interesting feature in Figure 6 is that the long-period perturbations are clearer at magnetic latitudes above $70^{\circ}$ and become almost unidentifiable at lower latitudes, such as at GILL and ISLL. Because the high-latitude areas in the nightside ionosphere map along geomagnetic field lines to the magnetotail, it can be inferred from Figure 6 that the corresponding magnetospheric perturbations originate in the tail.

Finally, we compare the magnetometer records at different longitudes. In Figure 7, magnetic perturbations at three stations located at nearly equal magnetic latitudes are shown. The longitudinal separation is $\sim 600 \mathrm{~km}$ between ATU and MCG and $\sim 1200 \mathrm{~km}$ between ATU and DNB. As shown in Figure 2, the ionospheric convection cell moves eastward, with an average velocity of $\sim 1.4 \mathrm{~km} \mathrm{~s}^{-1}$. If this velocity applies to the magnetometer perturbations, one would expect a time delay of $\sim 7$

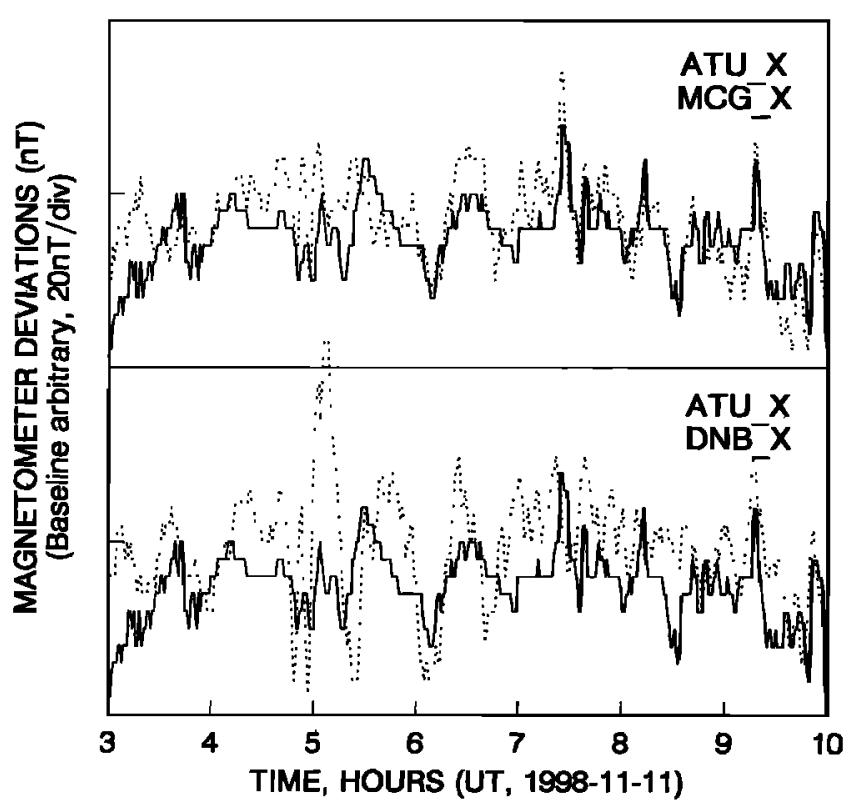

Figure 7. Comparison of magnetic deviations at different longitudes measured by three magnetometer stations located at the Greenland West Coast (ATU), the Greenland Central Ice Cap (MCG), and the Greenland East Coast (DNB). min between ATU and MCG and $\sim 14$ min between ATU and DNB. However, it is very difficult to identify these delays between the stations from Figure 7 , since the magnetic perturbations are too weak.

\section{Discussion}

As mentioned in Introduction, magnetospheric substorms may have a recurrence period of about 1 hour in the substorm onsets [Farrugia et al., 1993; Klimas et al., 1994; Siscoe et al., 1994; Shodhan et al., 1996]. A possible mechanism for the periodic recurrence of substorms is the pressure balance in the magnetotail. When the IMF is southward, dayside merging between the IMF and geomagnetic field lines transfers dayside flux onto the tail lobes, which increases the pressure on the plasma sheet. When the pressure reaches some critical value, a substorm is initiated, and the energy stored in the tail is released. If the IMF remains southward, this energy loading-unloading process can occur repeatedly. However, substorms occur during southward IMF and result in large perturbations in the nightside ionospheric currents. In the event presented in this paper the perturbations occurred during northward IMF, and the nightside ionospheric current perturbations were very weak. Obviously, the perturbations and corresponding mechanisms in the present event are different from those associated with substorms.

For southward IMF the magnetotail is highly stretched. With a long cylindrical model of the tail, McClay and Radiski [1967] and Ershkovich et al. [1972] showed that the tail might have some eigenmode fluctuations with periods 10-40 min. Chen and Kivelson [1991] observed fluctuations of magnetic field with a period $\sim 35 \mathrm{~min}$ in the lobes of the magnetosphere. They suggested that the 35-min fluctuations could be one of the magnetotail eigenmode fluctuations but indicated that more cases are needed to draw a conclusion. Furthermore, the 35 -min fluctuations were observed during substorms and should occur for southward IMF. Rinnert [1996] reported observations of quasiperiodic (40-60 min) enhancements of electron density in the auroral $E$ region and suggested that the periodic density enhancements were caused by periodic particle precipitation controlled by oscillations in the magnetotail. It was mentioned that no events could be found after long quiet intervals. At least a short period of increased geomagnetic activity must have happened before the periodic density enhancements were observed. In contrast, the periodic perturbations presented in this paper were observed after the IMF turned northward for 14 hours and were not associated with the increased geomagnetic activity prior to the quasiperiodic density enhancements. In addition, $E$ region density enhancements should increase the ionospheric conductivity and cause obvious magnetic deviations, but the magnetic perturbations in our event were very weak. In the event reported by Lessard et al. [1999], nearly monochromatic shortperiod (1-2 min) magnetic pulsations observed at the ground and on satellite were modulated with a 45-min periodicity. They suggested that a global disturbance could induce a radially polarized electric field in the $L$ value range of $6-10$; both the electron flux modulation and monochromatic pulsations were the consequence of the global disturbance. However, it was not possible to determine whether the source of the 45-min fluctuations in their event was in the solar wind or whether this frequency was intrinsic to the magnetosphere. The magnetometer at the south pole station showed oscillations with half the period of the magnetospheric electron flux modulations in their case. In 
our event, the magnetospheric and ionospheric perturbations showed the same periodicity.

For northward IMF quasisinusoidal fluctuations in the Pc5 period range (1-10 $\mathrm{min}$ ) were observed on the magnetopause [Kivelson and Chen, 1995] and were interpreted as KelvinHelmholtz surface waves. Papitashvili et al. [1996] presented observations of ground magnetic disturbances in the southern polar cap during a several-hour interval of northward IMF. The spectra of the disturbances showed peaks at $\sim 15 \mathrm{~min}$ and $\sim 60$ min, while that study dealt with $15-$ min pulsations. Huang et al. [2000a] first focused upon long-period (40-60 min) ionospheric disturbances during an extended interval of northward IMF. In the event reported by Huang et al. [2000a], ionospheric disturbances and atmospheric gravity waves with a period of $\sim 40$ min were observed after $B_{z}$ was small $\left(\left|B_{\bar{z}}\right| \sim 1 \mathrm{nT}\right)$ for 17 hours and then became positive for 4 hours. The $K p$ index was 0 when the ionospheric disturbances occurred. In the event presented in this paper, $B_{z}$ was positive for 14 hours before the magnetospheric-ionospheric perturbations with periods $50-60$ min were observed; the $K p$ index was also near 0 (see Figure 1). We think that the ionospheric perturbations in the previous event [Huang et al., 2000a] and in the present event could be associated with the same or similar source mechanism; the difference in the periodicity could be caused by different solar wind/IMF parameters and resultant extent of the magnetospheric tail.

In the event of Huang et al. [2000a], it was not possible to determine whether the ionospheric disturbances traveled along some specific direction. In the event presented in this paper, during the last half of each oscillation the ionospheric convection cell traveled eastward with a mean velocity of $\sim 1.4 \mathrm{~km} \mathrm{~s}^{-1}$, as shown in Figure 2. However, it was not possible to determine the propagation delay from ground magnetometer records because the magnetic perturbations were too weak. This is not surprising, given that the ionospheric conductivity would be very low in the nightside winter auroral zone after the extended period of northward IMF.

We now discuss the source mechanism of the long-period perturbations. It is well known that perturbations in the solar wind/IMF can result in similar perturbations in the magnetosphere and ionosphere. In the present event we are interested in the interval of 0230-0930 UT on November 11, 1998, as indicated by the vertical dashed lines in Figure 1. During this interval the solar wind velocity and density were relatively stable. The IMF components showed some fluctuations between 0500 and $0700 \mathrm{UT}$, but these fluctuations did not exist for the entire interval. In contrast, periodic perturbations were observed for the 7-hour interval in the magnetosphere and ionosphere, as shown in Plate 1 and Figures 4 and 5. Therefore we do not think that the magnetospheric-ionospheric perturbations were driven directly by solar wind/IMF perturbations. Instead, we suggest that the long-period perturbations are a natural oscillation mode in the magnetosphere; the initiation of the oscillations might be associated with solar wind/IMF perturbations.

We think that the tail acts as a large three-dimensional cavity within which various standing wave patterns can occur and that during northward IMF, some of the natural periods associated with those patterns will be from 40 to $60 \mathrm{~min}$. The shape of the cavity has been the subject of several studies. Sibeck et al. [1985] found that there is an elliptical cross section of the tail in the $Y-Z$ plane (GSM coordinates), with the tail being flattened in the $Z$ direction and more extended by a factor of 3 in the $Y$ direction, for a strong $12 \mathrm{nT}$ draping field. For a $5 \mathrm{nT}$ draping field the major axis was only $50 \%$ more than the minor axis [Sibeck et al., 1986]. More recently, Shodhan et al. [1996] considered the reasons for the Geotail mantle crossings in the tail at about $X=-170 R_{E}$ and found evidence for both windsock and breathing modes in the $Y-Z$ plane, with timescales of some tens of minutes. For northward IMF the MHD models of Bargatze et al. [1999] show that a cut of the tail in the $X-Z$ plane shows a rounded shape that looks quasidipolar but is really quite distorted from dipolar shape. It is certainly much different from the highly stretched tail shapes associated with southward IMF, as discussed by McBlay and Radiski [1967] and Ershkovich et al. [1972]. In the $X-Z$ plane the Bargatze et al. [1999] MHD model shows that the $X$ extent of the closed field line region is strongly dependent on the $B_{z}$ value of the IMF, and varies from about $X=-88 R_{E}$ for $B_{z}=$ $2.5 \mathrm{nT}$ to $X=-40 R_{E}$ for $B_{z}=5 \mathrm{nT}$ and finally to about $X=-29 R_{E}$ for $B_{z}=10 \mathrm{nT}$. In the simulations of Song et al. [1999] the tail lengths are 56 and $32 R_{E}$ for $B_{z}=5$ and $10 \mathrm{nT}$, respectively. For the conditions in the present paper, namely, a northward $B_{z}$ component in the range 3-6 nT, the tail length of the closed cavity would be about $50-80 R_{E}$. The fact that the closed field region is so sensitive to IMF changes means that a variable IMF will lead to very extensive expansions and contractions of the outer magnetosphere, even with relatively minor IMF variations.

The above results show that the three-dimensional shape of the magnetotail cavity is critically dependent on IMF conditions. In general, one would expect a complex set of standing wave modes in the magnetospheric cavity. The standing wave modes in such a cavity could be excited by various mechanisms, both internal and external to the magnetosphere, including the breathing, windsock, and wrenching mechanisms suggested by Shodhan et al. [1996]. Another example involves the simulations of Usadi et al. [1993]. They showed that large-scale twin vortices can be generated in the equatorial plane of the magnetosphere after the IMF turns northward for $\sim 1$ hour (their Figure 12a). They argued that the twin vortex structure is caused by the deformation of the magnetosphere from a stretched-tail shape to a more dipolar shape, but not due to a Kelvin- Helmholtz instability. The tail convection associated with the twin vortex structure maximizes around $X=-30 R_{E}$ and has the vorticity associated with the region 1 currents.

Let us now concentrate on the generation of long-period oscillations due to standing waves in the $X-Z$ plane of the tail. We propose that the periodic oscillations are excited by the movements of the closed tail boundary in response to the IMF. Such oscillations would lead to compressional waves. In turn, these waves would be reflected back at the near-Earth large pressure gradient region at about $X=-8 \sim-10 R_{E}$, with the result that a standing wave pattern is produced.

In the proposed scenario the oscillations of the tail boundary can be excited by the deformation and overshoot of the magnetosphere from a tail shape to a more dipolar shape or by IMF perturbations. Since the size of the closed magnetosphere is mainly determined by the magnitude of $B_{z}$, a large change in $B_{z}$ can cause the expansion and/or contraction of the closed magnetosphere and subsequent oscillations. This is also similar to the compression of the dayside magnetosphere by a solar wind pressure enhancement and subsequent oscillations at some intrinsic period. For the present event the IMF perturbations might play a role. The periodic ionospheric perturbations were observed 14 hours after $B_{z}$ turned northward. The tail oscillations excited by the first contraction of the magnetosphere could have been damped. As shown in Figure 1b, there were fluctuations in 
the three IMF components between 0030 and 0230 UT; these IMF fluctuations might have been capable of exciting the tail oscillations. After excitation the magnetospheric oscillations would continue at the natural resonant period, until they are damped due to energy dissipation. The IMF perturbations between 0500 and 0700 UT might have enhanced the tail oscillations. We suggest that the magnetospheric oscillations occur at an intrinsic frequency determined by the tail length; the function of IMF perturbations is to excite or enhance the magnetospheric oscillations.

We can estimate the period of the tail oscillations by assuming that the magnetotail cavity resonates due to the standing waves produced by compressional (magnetosonic) waves propagating between the near-Earth and distant boundaries. Under this approximation the period is given by

$$
T=\frac{2 l}{v_{c}}
$$

where $l$ is the distance between the boundaries, and $v_{\mathrm{c}}$ is the velocity of the compressional wave.

In the simulations of Bargatze et al. [1999], the outer boundary of the closed tail is at $X=-40 R_{E}$ for IMF $B_{z}=5 \mathrm{nT}$ and at $X=-88 R_{E}$ for IMF $B_{z}=2.5 \mathrm{nT}$. The plasma pressure at the outer boundary of the closed tail is $\sim 0.5 \times 10^{-11} \mathrm{~Pa}$ for IMF $B_{z}=5$ $\mathrm{nT}$ and $\sim 1 \times 10^{-11} \mathrm{~Pa}$ for IMF $B_{z}=2.5 \mathrm{nT}$, increases toward the Earth, and reaches a peak value $\sim 8 \times 10^{-11} \mathrm{~Pa}$ at about $X=-10 R_{E}$. The average pressure is $\sim 3 \times 10^{-11} \mathrm{~Pa}$ between the outer boundary and the peak position. The geomagnetic field is almost constant $\left(\sim 11.5 \mathrm{nT}\right.$ for IMF $B_{z}=5 \mathrm{nT}$ and $\sim 3.5 \mathrm{nT}$ for IMF $\left.B_{z}=2.5 \mathrm{nT}\right)$ between the outer boundary and the pressure maximum but suddenly increases at about $X=-10 R_{E}$. In the simulations of Usadi et al. [1993], the plasma temperature in the closed magnetosphere is almost constant at $\sim 200 \mathrm{eV}$ after a 90-min interval of northward IMF.

In the present event, $B_{z}$ was 3-4.5 nT with a mean value of 3.2 $\mathrm{nT}$ over the interval 0230-0930 UT. Using a linear interpolation of the simulation results of Bargatze et al. [1999], we find that the outer boundary of the tail should be about $X=-75 R_{E}$ and the geomagnetic field about $6 \mathrm{nT}$. We assume an isothermal plasma with $T_{i}=T_{e}=200 \mathrm{eV}$ and average plasma pressure of $3 \times 10^{-11} \mathrm{~Pa}$. Thus the average ion density is $\sim 0.5 \mathrm{~cm}^{-3}$. Accordingly, the Alfven velocity is $185 \mathrm{~km} \mathrm{~s}^{-1}$. The assumed ion density and Alfven velocity agree with estimates by other authors. For example, the typical near-tail plasma density given by Hughes [1995] is $0.01 \mathrm{~cm}^{-3}$ in the tail lobe, $0.1 \mathrm{~cm}^{-3}$ in the plasma sheet boundary layer, and $0.3 \mathrm{~cm}^{-3}$ in the central plasma sheet; $M c C l a y$ and Radiski [1967] took the Alfven velocity to be $200 \mathrm{~km} \mathrm{~s}^{-1}$ in their calculations of magnetic fluctuations in the magnetotail. In the present case the magnetotail would have been highly contracted after the extended interval of northward IMF. Consequently, the plasma density could have been higher, and the Alfven velocity could have been lower.

The relationship between the compressional wave velocity and Alfven velocity is given by [Kivelson, 1995]

$$
v_{c}^{2}=\frac{1}{2}\left\{c_{s}^{2}+v_{A}^{2} \pm\left[\left(c_{s}^{2}+v_{A}^{2}\right)^{2}-4 c_{s}^{2} v_{A}^{2} \cos ^{2} \theta\right]^{1 / 2}\right\},
$$

where $v_{A}$ is the Alfven velocity, $c_{S}$ is the ion acoustic velocity, and $\theta$ is the angle between the magnetic field and wave vector. The ion acoustic velocity is given by

$$
c_{s}=\left[\frac{\gamma k_{B}}{m_{p}+m_{e}}\left(T_{p}+T_{e}\right)\right]^{1 / 2},
$$

where $y$ is the ratio of specific heats, $k_{B}$ is the Boltzmman constant, $m_{p}\left(m_{e}\right)$ is the proton (electron) mass, and $T_{p}\left(T_{e}\right)$ is the proton (electron) temperature. With $T_{p}=T_{e}=200 \mathrm{eV}$ and $\gamma=1$ (isothermal plasma), the ion acoustic velocity is $196 \mathrm{~km} \mathrm{~s}^{-1}$.

Using $v_{A}=185 \mathrm{~km} \mathrm{~s}^{-1}$ and $c_{s}=196 \mathrm{~km} \mathrm{~s}^{-1}$ and taking $\theta=90^{\circ}$, we find that the velocity of the fast-mode wave is $270 \mathrm{~km} \mathrm{~s}^{-1}$. We assume that the compressional waves propagate between the outer boundary of the closed tail at $X=-75 R_{E}$ and the near-Earth boundary at $X=-10 R_{E}$ over a distance $l=65 R_{E}$. Therefore the period of the standing wave tail oscillations would be about 51 min, which is double the 25.5-min one-way travel time of the compressional waves from $X=-75 R_{E}$ to $X=-10 R_{E}$. This agrees reasonably well with the observations.

We can now address the question of why the ionospheric convection patterns observed by the radars are seen to exhibit the long-period oscillations at lower latitudes rather than at the high latitudes that would map out to the tail at 50-80 $R_{E}$. The answer may be similar to the effect found in the simulations of Birn and Hesse [1996] for substorm conditions. They showed that, although midtail reconnection during substorms occurred near $X=-23 R_{E}$, the resulting field-aligned currents to the ionosphere were concentrated near $X=-13 R_{E}$, far from the reconnection site, even though the reconnection is the ultimate energy source for the currents.

This type of scenario could be extended to the standing wave pattern in the $X-Z$ plane that we propose above for positive $B_{z}$ conditions. If the waves are not completely reflected at $X \sim-10$ $R_{E}$, that is, if the boundary there is not totally fixed but is partially free, then it would be likely that some energy would be transferred from the standing wave pattern to the convection pattern at these near-Earth distances. Suppose that there is a global earthward electric field [Lessard et al., 1999]. This electric field will drive plasma to move eastward in the magnetosphere and ionosphere. The resulting lower-latitude convection pattern would exhibit the eastward motion caused by the radially inward electric field, and the convection would certainly be strongly influenced by the periodicity of the standing wave mode.

In our event the ionospheric convection vortex formed around $0200 \mathrm{MLT}$ near magnetic latitude $70^{\circ}$. For a dipolar geometry the relationship between the $L$ value in the equatorial plane and the magnetic latitude $\theta_{0}$ of the field line on the Earth's surface is given by

$$
\theta_{0}=\cos ^{-1}\left(\frac{1}{\sqrt{L}}\right)
$$

For $\theta_{0}=70^{\circ}$, the $L$ value is $\sim 8.5$. This is consistent with the assumed inner reflection boundary of the compressional waves and the location with large change in plasma pressure and geomegnetic field in the simulations of Bargatze et al. [1999].

The combined radar, magnetometer, and satellite observations presented in this paper have revealed some significant characteristics of the long-period magnetospheric-ionospheric perturbations during northward IMF. As discussed above, the magnetospheric-ionospheric perturbations in the present event and the previous event of Huang et al. [2000a] might have the same or similar generation mechanism. However, the period of the perturbations is $-40 \mathrm{~min}$ in the previous event and $\sim 54 \mathrm{~min}$ in the present event. If the mechanism suggested in this paper is 
correct, it implies that the tail length is different in the two events. A shorter period of the perturbations means a smaller extent of the magnetospheric cavity. This is likely because the magnetospheric geometry is sensitively dependent on the solar wind and IMF parameters, as shown in the simulations of Bargatze et al. [1999]. Assuming that the geomagnetic field and plasma parameters were the same in the two events, one could roughly estimate that the outer boundary of the closed tail might be at about $X=-61 R_{E}$ in the previous event and at about $X=-75$ $R_{E}$ in the present event, respectively. Therefore it will be possible to infer the magnetospheric cavity shape from the periodicity of magnetospheric oscillations during prolonged northward IMF, if the periodicity is indeed determined by the size of the cavity and if the field and plasma parameters in the magnetosphere are measured.

However, many questions remain unanswered. For example, it is not clear whether the ionospheric convection is symmetric with respect to the noon-midnight meridian; the radar data showed only the portion of the convection in the postmidnight sector. The present studies use radar and magnetometer data only from the Northern Hemisphere; it is necessary to investigate the conjugate properties of the perturbations in both hemispheres if the magnetospheric-ionospheric perturbations are truly a global oscillation. It is also unclear how other IMF components $\left(B_{x}\right.$ and $\left.B_{y}\right)$ and solar wind pressure play a role in determining the period of the perturbations. The assumed earthward electric field in the magnetosphere has not been verified. It is not fully understood why the convection cell does not move for the first 30-min of each cycle and what determines the final position of the cell at $\sim 0600$ MLT. It is necessary to compare the distinctive regions in the magnetosphere predicted by the simulations [Bargatze et al., 1999; Song et al., 1999] with direct measurements. More observational and simulation efforts are required to verify the proposed mechanism. We plan further studies in the above areas in the future.

\section{Summary}

The IMF turned northward at 1300 UT on November 10 , 1998 , and remained northward for 29 hours. The $K p$ index was not larger than $1+$ over the entire interval. We have observed, for the first time, long-period magnetospheric-ionospheric perturbations with HF radars, ground-based magnetometers, and satellite magnetometers, during this prolonged interval of northward IMF. The major findings are as follows.

1. After the IMF tumed northward for 14 hours, the Iceland West $\mathrm{HF}$ radar observed periodic $F$ region ionospheric velocity perturbations in the postmidnight/dawn sector between 0300 and 1000 UT on November 11, 1998. Seven cycles of velocity perturbations were clearly identifiable. The velocity perturbations showed periods 50-60 min, with a mean period $\sim 54 \mathrm{~min}$. The amplitude of the line-of-sight velocity perturbations was $\sim 500 \mathrm{~m} \mathrm{~s}^{-1}$, corresponding to electric field perturbations with an amplitude $\sim 30 \mathrm{mV} \mathrm{m}^{-1}$.

2. For each cycle of the convection perturbations, a largescale, counterclockwise convection cell formed around 0200 MLT near magnetic latitude $70^{\circ}$. The flow intensity associated with the convection cell grew for $\sim 30 \mathrm{~min}$, while the cell position remained nearly unchanged. The convection cell then started to move eastward. The eastward motion of the cell took $\sim 20 \mathrm{~min}$; the final position of the cell focus was around 0600 MLT between magnetic latitudes $75^{\circ}$ and $80^{\circ}$. The mean eastward velocity of the cell shift was $\sim 1.4 \mathrm{~km} \mathrm{~s}^{-1}$ during this 20 -min interval.

3. Ground-based magnetometers recorded quasiperiodic magnetic perturbations with periods $50-60 \mathrm{~min}$ in both premidnight and postmidnight sectors. The magnetic perturbations had an amplitude 3-5 nT above magnetic latitude $70^{\circ}$ and became very weak below that latitude. The low conductivity of the quiet nightside ionosphere would not allow effective coupling of the wave through the ionosphere, with the result that the signal seen on the ground would be significantly attenuated.

4. At the GOES 8 satellite which was nearly in the equatorial plane of the magnetosphere during the period of interest, magnetic field perturbations were also observed with periods 50 60 min at $L \sim 6$ on the nightside. The magnetospheric magnetic field perturbations were well correlated with the ionospheric electric field perturbations, indicating that the magnetospheric and ionospheric perturbations had a common source.

5. We propose the following mechanism for the generation of the long-period magnetospheric-ionospheric perturbations. After the IMF turns northward for a few hours, the magnetosphere becomes largely closed. The deformation of the magnetosphere from a tail shape to a dipolar shape or IMF fluctuations can excite oscillations in the closed tail. The period of the global tail oscillations is determined by the radial extent of the closed tail. The oscillations at the outer boundary of the tail are transmitted earthward at the speed of compressional waves, forming a standing wave pattern when there is partial reflection at a "leaky" boundary at about $X \sim-10 R_{E}$. As a result of energy leakage at this boundary, some of the compressional wave energy may couple into convection and field-aligned currents. The latter are generated at tail distances near the leaky inner boundary because there is an interface there between two distinct flow regions, as inferred from the corresponding radar flows in the ionosphere. The field-aligned currents result in the generation of large-scale ionospheric convection vortices on the nightside. For an average $B_{2}$ value of 3-6 nT over several hours, consistent with the observations, the period of the magnetospheric-ionospheric perturbations is expected to be in the range 40-60 min. This period is determined by a natural resonant period of the magnetic cavity, possibly associated with the compressional wave travel time between the inner and outer boundaries of the cavity.

Acknowledgments. We acknowledge the CDAWeb for access to the Wind data and thank H. J. Singer of NOAA Space Environment Center for providing the GOES 8 data. The CUTLASS radars are funded by the Particle Physics and Astronomy Research Council, U.K., under grant PPA/R/R/1997/00256, the Finnish Meteorological Institute, Helsinki, and the Swedish Institute for Space Research, Uppsala. Operation of the Goose Bay radar is supported by the NSF under grant ATM-9812078. Operation of the Kapuskasing radar is supported by NASA under grant NAG5-8361. Operation of the Stokkseyri radar is supported by INSU of France. Funding for the Saskatoon radar and the Canadian SuperDARN team is supported by NSERC CSPP, MFA, CRO, and Operating Research grants for the Canadian Component of SuperDARN. The CANOPUS magnetometers are supported by Canadian Space Agency. The Greenland magnetometers are operated by the Danish Meteorological Institute and by the University of Michigan with support from NSF award OPP-9876473. The MACCS project is supported by the NSF under grant ATM-9704766 to Boston University and grant ATM9610072 to Augsburg College.

Janet G. Luhmann thanks Allan T. Weatherwax and another referee for their assistance in evaluating this paper. 


\section{References}

Bargatze, L. F., T. Ogino, R. L. McPherron, and R. J. Walker, Solar wind magnetic field control of magnetospheric response delay and expansion phase onset timing, J. Geophys. Res., 104, 14,583, 1999.

Birn, J., and M. Hesse, Details of current disruption and diversion in simulations of magnetotail dynamics, J. Geophys. Res., 101, 15,345, 1996.

Borovsky, J. E., R. J. Nemzek, and R. D. Belian, The occurrence rate of magnetospheric-substorm onsets: Random and periodic substorms, $J$. Geophys. Res., 98, 3807, 1993.

Chen, S. H., and M. G. Kivelson, On ultralow frequency waves in the lobes of the Earth's magnetotail, J. Geophys. Res., 96, 15,711, 1991.

Ershkovich, A. I., A. A. Nusinov, and A. A. Chemikov, Nonlinear waves in geomagnetic wake, J. Geophys. Res., 77, 6907, 1972.

Farrugia, C. J., M. P. Freeman, L. F. Burlaga, R. P. Lepping, and K. Takahashi, The Earth's magnetosphere under continued forcing: Substorm activity during the passage of an interplanetary magnetic cloud, J. Geophys. Res., 98, 7657, 1993.

Greenwald, R A., et al., DARN/SuperDARN, A global view of the dynamics of high-latitude convection, Space Sci. Rev., 71, 761, 1995.

Huang, C. S., G. J. Sofko, A. V. Kustov, J. W. MacDougall, D. A. Andre, W. J. Hughes, and V. O. Papitashvili, Quasi-periodic ionospheric disturbances with a 40-min period during prolonged northward interplanetary magnetic field, Geophys. Res. Lett., 27, 1795, 2000a.

Huang, C. S., G. J. Sofko, A. V. Kustov, D. A. Andre, J. M. Ruohoniemi, R. A. Greenwald, and M. R. Hairston, Evolution of ionospheric multicell convection during northward interplanetary magnetic field with $\left|B_{z} / B_{v}\right|>1$, J. Geophys. Res., 105, 27,095, $2000 \mathrm{~b}$.

Hughes, W. J., The magnetopause, magnetotail, and magnetic reconnection, in Introduction to Space Physics, edited by M. G. Kivelson and C. T. Russell, p. 227, Cambridge Univ. Press, New York, 1995.

Hughes, W. J., and D. J. Southwood, The screening of micropulsation signals by the atmosphere and ionosphere, J. Geophys. Res., 81, 3234, $1976 \mathrm{a}$.

Hughes, W. J., and D. J. Southwood, An illustration of modification of geomagnetic pulsation by the ionosphere, J. Geophys. Res., 81, 3241, $1976 \mathrm{~b}$.

Kivelson, M. G., Pulsations and magnetohydrodynamic waves, in Introduction to Space Physics, edited by M. G. Kivelson and C. T. Russell, p. 330, Cambridge Univ. Press, New York, 1995.

Kivelson, M. G., and S. H. Chen, The magnetopause: Surface waves and instabilities and their possible dynamic consequences, in Physics of the Magnetopause, Geophys. Monogr. Ser., vol. 90, edited by P. Song, B. U. O. Sonnerup, and M. F. Thomsen, pp. 257-268, AGU, Washington, D. C., 1995.

Klimas, A. J., D. N. Baker, D. Vassiliadis, and D. A. Roberts, Substorm recurrence during steady and variable solar wind driving: Evidence for a normal mode in the unloading dynamics of the magnetosphere, J. Geophys. Res., 99, 14,855, 1994.

Lessard, M. R., M. K. Hudson, B. J. Anderson, R. L. Arnoldy, H. Luhr, G. D. Reeves, N. Sato, and A. T. Weatherwax, Evidence for a global disturbance with monochromatic pulsations and energetic electron bunching, J. Geophys. Res., 104, 7011, 1999.

McClay, J. F., and H. R. Radiski, Hydromagnetic propagation in a thetamodel geomagnetic tail, J. Geophys. Res., 72, 4525, 1967.

Papitashvili, V. O., C. R. Clauer, S. B. Musko, B. A. Belov, O. A. Troshichev, and M. G. Gudkov, Low-magnitude, long-period magnetic pulsations observed deep in the southern polar cap, Aniarct. J. U. S., 31, 257, 1996 .
Rinnert, K., Quasi-periodic precipitation with periods between 40 and 60 minutes, Ann. Geophys., 14, 707, 1996.

Ruohoniemi, J. M., and K. B. Baker, Large-scale imaging of highlatitude convection with Super Dual Auroral Radar Network HF radar observations, J. Geophys. Res., 103, 20,797, 1998.

Ruohoniemi, J. M., and R. A. Greenwald, Statistical pattems of highlatitude convection obtained from Goose Bay HF radar observations, J. Geophys. Res., 101, 21,743, 1996.

Shodhan, S., G. L. Siscoe, L. A. Frank, K. L. Ackerson, and W. R. Paterson, Boundary oscillations at Geotail: Windsock, breathing, and wrenching, J. Geophys. Res., 101, 2577, 1996.

Sibeck, D. G., G. L. Siscoe, J. A. Slavin, E. J. Smith, and B. T. Tsurutani, The distant magnetotail's response to a strong interplanetary magnetic field $B_{y}$ : Twisting, flattening, and field line bending, $J$. Geophys. Res. 90, 4011, 1985.

Sibeck, D. G., G. L. Siscoe, J. A. Slavin, and R. P. Lepping, Major flattening of the distant geomagnetic tail, J. Geophys. Res., 91, 4223, 1986.

Siscoe, G. L., L. A. Frank, K. L. Ackerson, and W. R. Paterson, Irregular, long-period boundary oscillations beyond $\sim 100 R_{E}$ : Geotail plasma observations, Geophys. Res. Lett., 21, 2979, 1994.

Song, P., D. L. DeZeeuw, T. I. Gombosi, C. P. T. Groth, and K. G. Powell, A numerical study of solar wind-magnetospheric interaction for northward interplanetary magnetic field, J. Geophys. Res., 104, 28,361, 1999.

Usadi, A., A. Kageyama, K. Watanabe, and T. Sato, A global simulation of the magnetosphere with a long tail: Southward and northward interplanetary magnetic field, J. Geophys. Res., 98, 7503, 1993.

R. A. Greenwald, and J. M. Ruohoniemi, Applied Physics Laboratory, Johns Hopkins University, 11100 Johns Hopkins Road, Laurel, MD 20723-6099 (mike.ruohoniemi@jhuapl.edu; ray.greenwald@jhuapl.edu)

C. S. Huang, Haystack Observatory, Massachusetts Institute of

Technology, Route 40, Westford, MA 01886. (cshuang@haystack.mit.edu)

W. J. Hughes, Center for Space Physics, Boston University, 725 Commonwealth Avenue, Boston, MA 02215. (hughes@buasta.bu.edu)

A. V. Koustov and G. J. Sofko, Institute of Space and Atmospheric Studies, University of Saskatchewan, 116 Science Place, Saskatoon, SK S7N 5E2, Canada. (kustov@dansas.usask.ca; sofko@dansas.usask.ca)

M. Lester, Department of Physics and Astronomy, University of Leicester, Leicester LE1 7RH, UK. (mle@ion.le.ac.uk)

J. W. MacDougall, Department of Electrical Engineering, University of Western Ontario, London, ON. N6A 5B9, Canada (jmacdoug@julian.uwo.ca)

V. O. Papitashvili, Space Physics Research Laboratory, University of Michigan, Ann Arbor, MI 48019. (papita@umich.edu)

J.-P. Villain, Centre National de la Recherche Scientifique, Laboratoire de Physique et Chemie de l'Environnement (CNRS/LPCE), 3A, Avenue de la Recherche Scientifique, 45071 Orléans Cedex 2, France. (jvillain@odyssee.cnrs-orleans.fr)

J. Watermann, Danish Meteorological Institute, Solar-Terrestrial Physics Division, Lyngbyvej 100, DK-2100 Copenhagen O, Denmark. (jww@dmi.dk)

(Received May 30, 2000; revised September 19, 2000; accepted October 12, 2000) 